\title{
ANTIBACTERIAL AND ANTIOXIDANT ACTIVITIES OF ACID AND BILE RESISTANT STRAINS OF LACTOBACILLUS FERMENTUM ISOLATED FROM MIANG
}

\author{
Srikanjana Klayraung ${ }^{1}$; Siriporn Okonogi $^{2} *$ \\ ${ }^{1}$ Faculty of Science, Maejo University, Chiang Mai 50290, Thailand; ${ }^{2}$ Faculty of Pharmacy, Chiang Mai University, Chiang \\ Mai 50200, Thailand.
}

Submitted: June 18, 2008; Returned to authors for corrections: January 12, 2009; Approved: June 28, 2009.

\begin{abstract}
Miang is a kind of traditional fermented tea leaves, widely consumed in northern Thailand as a snack. It contains several kinds of Lactobacilli spp. The aim of this study was to isolate strains of Lactobacillus fermentum from miang and to investigate their antibacterial and antioxidant activities. The agar spot and well assays were used for determination of antibacterial power. The antibacterial mechanism was investigated by cell morphologic change under scanning electron microscope (SEM). Antioxidant activity was studied by means of free radical scavenging and ferric reducing power assays. The acid and bile screening tests indicated that L. fermentum FTL2311 and L. fermentum FTL10BR presented antibacterial activity against several pathogenic bacteria: Listeria monocytogenes DMST 17303, Salmonella Typhi DMST 5784, Shigella sonnei DMST 561 (ATCC 11060) and Staphylococcus aureus subsp. aureus DMST 6512 (ATCC 6538Ptm). The results from SEM suggested that the antibacterial action was due to the destruction of cell membrane which consequently caused the pathogenic cell shrinking or cracking. The antioxidant study suggested that both L. fermentum FTL2311 and L. fermentum FTL10BR strains could liberate certain substances that possessed antioxidant activity expressed as trolox equivalent antioxidant capacity (TEAC) and equivalent concentration (EC) values for free radical scavenging and reducing mechanisms, respectively. The supernatant of $L$.

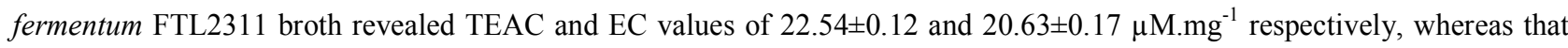


strains isolated from miang present high potential as promising health-promoting probiotics.
\end{abstract}

Key words: Lactobacillus fermentum, miang, bile resistance, antibacterial activity, antioxidant activity

\section{INTRODUCTION}

Some lactic acid bacteria (LAB) have been widely used as probiotics for human and animals $(23,30)$. To be a good or highly potential probiotic, some properties are required. Besides the safety and ability to adhere the host intestinal epithelium, the properties of high tolerance to an extremely stressed condition in gastrointestinal (GI) tract are of the most important issue. Moreover the good probiotics should have other abilities such as antagonistic activity against pathogenic bacteria and antioxidant activity in order to enhance health promotion of the host $(8,18,26)$.

*Corresponding Author. Mailing address: Faculty of Pharmacy, Chiang Mai University, Chiang Mai, 50200, THAILAND.; Tel: +66-53-944311; Fax: +6653-222741.; E-mail: sirioko@,chiangmai.ac.th 
According to the GI stress condition, bile tolerance is of the most pronounced properties required for probiotic LAB to survive in the small intestine $(20,23,27,31)$. Generally, the bile salts are released into the upper small intestine after ingestion of fatty meals and they have a detergent-like function. Since these compounds are toxic for microbial cell membranes which composed of lipids and fatty acids, the autochthonous gastrointestinal microbiota must have developed strategies to defend themselves against the toxic action of bile, although these mechanisms still remain poorly understood (3). Bile concentration of the GI tract usually varies in a wide range depending on various factors of food and intrinsic secretion as well as transient time. The probiotic with strong tolerance to high bile concentration and with particularly health enhancing properties such as antibacterial and antioxidant are of the most promising strains.

Lactobacillus fermentum is one of the potential probiotic LAB and reported to be able to adhere to the epithelial cells, with a preference for the small intestine $(11,30)$. It shows high ability to colonize in intestine after oral administration $(28,33)$. Most isolated strains of L. fermentum have been reported to resist to some extent of bile salt concentration but not exceed that $0.5 \%(9,17)$. However, the high concentration of bile in human was reported up to approximately $8 \%$ in the gall bladder and $2 \%$ in the intestine (10). Therefore, it is necessary to search for the strains with sufficient ability to resist higher bile concentration. The antimicrobial activity of $L$. fermentum was also reported by many authors $(2,17,29,37,38,39)$. However, the research on how the pathogens had been destroyed was rare. Besides the search for the potential L. fermentum strains that strongly resist high concentration of bile salt, this research was also carried out to determine the antibacterial activity of selected strains and to possibly explain the mechanism of antibacterial action. In addition, the antioxidant activity of selected strains was also investigated since antioxidation is recently one of the most interesting issues having high impact of prevention and treatment of many reverse chronic diseases caused by oxidation degeneration.
Miang, a traditional fermented food product, made of tea leaves is very well known and consumed as a common snack in Thailand. The manufacturing process of miang includes many steps of biotechnology. Young tea leaves are collected, steamed, wrapped tightly in individual bundles, packed into containers, pressed tightly and weighted down, covered with banana leaves, then fermented for three months. The product has a pickled flavor, sour and flowery (14). Various strains of LAB including Lactobacillus sp., Pediococcus sp. and Enterococcus sp. were reported to be isolated from miang (36) indicating that it can be one of the promising sources of probiotic bacteria. Hence, in this study, miang was used as the material for searching the desired strains mentioned earlier. The use of miang was also highlighted by the facts that it is a common consumption in Thailand and readily available.

\section{MATERIALS AND METHOD}

\section{Isolation of Lactobacillus strains}

Samples of miang were collected from local markets in Chiang Mai area, Thailand. Appropriately diluted samples with saline solution $(0.85 \%$ sodium chloride $)$ were plated onto de Man-Rogosa-Sharpe (MRS) agar (Merck, Darmstadt, Germany), and incubated at $37^{\circ} \mathrm{C}$ under anaerobic condition for $48 \mathrm{~h}$. Based on the phenotypic characteristics (colony characteristics, gram staining, cell shape, and catalase production), isolates of lactobacilli were collected. The selected strains were identified by API $50 \mathrm{CHL}$ kit (bioMerieux, Lyon, France) and confirmed by mean of species specific PCR $(15,34)$ before storing in MRS containing $20 \%$ glycerol (BDH Chemical, UK) at $-20^{\circ} \mathrm{C}$ for further studies.

\section{Pathogenic bacteria}

Listeria monocytogenes DMST 17303, Salmonella Typhi DMST 5784, Shigella sonnei DMST 561 (ATCC 11060), and Staphylococcus aureus subsp. aureus DMST 6512 (ATCC $6538 \mathrm{Ptm}$ ) obtained from the Culture Collection for Medical 
Microorganism, Department of Medical Sciences Thailand (DMST culture collection) were used as test bacteria. They were maintained by routine culture on trypticase soy agar (TSA, Merck, Germany) with $0.5 \%$ yeast extract and were stored in trypticase soy broth (TSB, Merck, Darmstadt, Germany) containing $20 \%$ glycerol at $-20^{\circ} \mathrm{C}$.

\section{Study on bile tolerance of $\boldsymbol{L}$. fermentum}

According to Mojgani et al. (22) and Deraz et al. (5), series of MRS broth with $0.3,0.5,1,2,3,4$, and $5 \%(\mathrm{w} / \mathrm{v})$ of bile were prepared by adding appropriate amount of oxgall (Difco, Detroit, MI, USA) to the broth. The cells from a 100 $\mathrm{ml} 16 \mathrm{~h}$ at $37^{\circ} \mathrm{C}$ MRS culture of L. fermentum were collected after centrifugation $\left(3,500 \times \mathrm{g}, 20 \mathrm{~min}, 4^{\circ} \mathrm{C}\right)$, washed twice in saline solution and resuspended in $10 \mathrm{ml}$ MRS broth. This suspension was inoculated $(1 \% \mathrm{v} / \mathrm{v})$ into MRS broth with or without bile. After 0, 1, 2, 3, 4, 6, 8, 10 and $24 \mathrm{~h}$ of incubation at $37^{\circ} \mathrm{C}$, optical density of the culture at $600 \mathrm{~nm}$ were determined. The bile tolerance of each strain was based on the time in minutes required for the absorbance value to increase by 0.3 units. Delay of growth was based on the time required for each culture to reach a 0.3 unit. According to Hyronimus et al. (12), the difference time between the control (growth in MRS broth without bile) and the test culture (growth in MRS broth with bile) was considered to be the delay in growth caused by inhibition of bile. Furthermore, after $24 \mathrm{~h}$ incubation, viable cell count was determined by plating serial dilutions (in 0.05 $\mathrm{M}$ phosphate buffer $\mathrm{pH}$ 7.0) on MRS agar. These plates were then incubated at $37^{\circ} \mathrm{C}$ in an anaerobic atmosphere for $48 \mathrm{~h}$. The percentage of growth was calculated as follows:

\section{Number of cfu in MRS}

\begin{tabular}{|c|c|}
\hline & with bile \\
\hline$\%$ growth = & Number of cfu in MRS \\
\hline
\end{tabular}

\section{Determination of antibacterial activity}

In this study, L. monocytogenes DMST 17303, S. Typhi DMST 5784, S. sonnei DMST 561 (ATCC 11060), and $S$. aureus subsp. aureus DMST 6512 (ATCC 6538Ptm) were used as the test pathogenic microorganisms. Two complementary methods of agar spot and agar well assays were used. In an agar spot test modified from the methods of Schillinger and Lücke (32) and Mante et al. (19), $1 \mu \mathrm{L}$ of each overnight culture of bacterial isolate was spotted on MRS plates containing $0.2 \%$ glucose and $1.2 \%$ agar. The MRS plates were incubated under microaerophilic condition for $48 \mathrm{~h}$ to develop colonies. Then, $10^{6} \mathrm{cfu} . \mathrm{mL}^{-1}$ of an overnight culture of test bacteria were inoculated in $9 \mathrm{~mL}$ of Mueller Hinton (Merck, Darmstadt, Germany) soft agar $(0.7 \%$ agar). The medium was immediately poured over the MRS plate on which the isolated L. fermentum was grown. The plates were incubated aerobically at $37^{\circ} \mathrm{C}$ for $24 \mathrm{~h}$. Following the incubation, the diameter of clear zone was determined. For an agar well assay, the freshly prepared cell free supernatant of L. fermentum FTL2311 and L. fermentum FTL10BR were used. The assay was done according to the method described by Papamanoli et al. (24). Melted and tempered Mueller Hinton agar was inoculated with pathogenic bacteria at $10^{6}$ cfu.mL $\mathrm{mL}^{-1}$ and poured into Petri dishes. Wells of $5 \mathrm{~mm}$ diameter were made and filled with 50 $\mu \mathrm{L}$ of cell free supernatant. Plates were incubated aerobically at $37^{\circ} \mathrm{C}$ for $24 \mathrm{~h}$. The antimicrobial effect of the supernatant was evaluated by measurement of clear zone. Each experiment was performed in four replicates.

\section{Determination of the effect of bile salt on antibacterial activity of $L$. fermentum}

Strains of L. fermentum FTL2311 or FTL10BR were inoculated in MRS broth and MRS broth with and without bile then cultivated under an anaerobic condition at $37^{\circ} \mathrm{C}$ for $24 \mathrm{~h}$. Cell free supernatant was prepared and investigated for antibacterial activity against $S$. aureus subsp. aureus DMST 6512 (ATCC 6538Ptm) by agar well assay. 


\section{Preparation of cell free supernatant}

Each MRS broth with or without bile salt was each inoculated with $1 \%(\mathrm{v} / \mathrm{v})$ of an overnight culture of $L$. fermentum FTL2311 or L. fermentum FTL10BR. After incubation for $24 \mathrm{~h}$, the cells were removed by centrifugation at $3,500 \times \mathrm{g}$ for $20 \mathrm{~min}$ at $4^{\circ} \mathrm{C}$. The supernatant was neutralized to $\mathrm{pH} 7.0$, sterilized by filtration through a $0.2 \mu \mathrm{m}$ filter membrane (Sartorius, Göttingen, Germany) before used.

\section{Study of ultrastructural morphology of pathogenic bacteria}

In this study, $S$ aureus subsp. aureus DMST 6512 (ATCC 6538Ptm) and L. monocytogenes DMST 17303 were used as test pathogenic bacteria. The ultrastructural morphology of both pathogenic microorganisms was studied under SEM. Sample preparation method was according to Forestier et al. (8) with some modification. Briefly, the test pathogenic strains were cultured overnight in tryptic soy broth (TSB, Merck, Darmstadt, Germany). The supernatant was discarded, bacteria were washed once with phosphate buffered saline $(0.01 \mathrm{M}, \mathrm{pH} 7.2)$ and resuspended in TSB to an approximate density of $10^{7} \mathrm{cfu} \cdot \mathrm{mL}^{-1}$. The assay was performed by incubating $2.5 \mathrm{~mL}$ of this suspension with 2.5 $\mathrm{mL}$ of L. fermentum supernatant at $37^{\circ} \mathrm{C}$ for $18 \mathrm{~h}$. After incubation, $1 \mathrm{~mL}$ of this mixture was filtrated by membrane filter $(0.2 \mu \mathrm{m})$ as fixed to membrane; it was prefixed with $2 \%$ glutaraldehyde for $1 \mathrm{~h}$ and postfixed with $1 \%$ osmium tetrachloride for 2 to $3 \mathrm{~h}$. It was then dehydrated with gradient of absolute ethanol, subjected to critical point drying and gold plating, and observed under scanning electron microscope (SEM) model JSM 5910LV (JEOL Ltd., Tokyo, Japan).

\section{Determination of antioxidant activity of $L$. fermentum}

The antioxidant activity of $L$. fermentum FTL2311 and $L$. fermentum FTL10BR was investigated by means of two potential antioxidant methods; 2,2'-azino-bis-(3ethylbenzothiazoline-6-sulfonic acid) diammonium salt (ABTS) free radical scavenging and ferric reducing ability of plasma (FRAP) assays described previously (35) with some minor modification. Briefly for ABTS assay, the supernatant was diluted in ethanol to yield a concentration of $1 \mathrm{mg} \cdot \mathrm{mL}^{-1}$. An aliquot of $20 \mu \mathrm{L}$ of this solution of each strain was added to $180 \mu \mathrm{L}$ of ABTS free radical cation solution. The absorbance, monitored for $5 \mathrm{~min}$, was measured spectrophotometrically at $750 \mathrm{~nm}$ using a microtitre plate reader. The free radical-scavenging activity of each sample was expressed as trolox equivalent antioxidant capacity (TEAC), which was obtained by comparing the absorbance change at $750 \mathrm{~nm}$ in a reaction mixture containing a supernatant with that containing standard trolox (Aldrich Chemical Company, Steinheim, Germany). This index is defined as the millimolar concentration of a trolox solution whose antioxidant capacity is equivalent to $1 \mathrm{mg}$ of the supernatant (1). According to the FRAP assay, the supernatant was dissolved in ethanol at a concentration of 1 $\mathrm{mg} \cdot \mathrm{mL}^{-1}$. An aliquot of $20 \mu \mathrm{L}$ test solution was mixed with $180 \mu \mathrm{L}$ of FRAP reagent. The absorption of the reaction mixture was measured at $595 \mathrm{~nm}$ by a microtitre plate reader. Ethanolic solutions of known Fe (II) concentration, in the range of $50-500 \mu \mathrm{M}\left(\mathrm{FeSO}_{4}\right)$, were used as calibration curve. The reducing power was expressed as equivalent concentration (EC). This parameter was defined as the concentration of antioxidant having a ferric reducing ability equivalent to that of $1 \mathrm{mM} \mathrm{FeSO}_{4}$. Primrose oil was used as a positive control.

\section{RESULTS AND DISCUSSION}

Twenty four strains of Lactobacillus sp. were isolated from miang. Results of the primary screening probiotic properties found that 10 out of 41 isolates could be classified as acid and bile tolerant strains with other essential probiotic characteristics. Among these, strains no. FTL2311 and FTL10BR exhibited the highest acid resistance with the survival rates of more than $50 \%$ after $2 \mathrm{~h}$ exposure to an extremely low $\mathrm{pH}$ of 2.0. Moreover, these two strains pronounced the survival rate of more than $90 \%$ in $1.0 \%$ of 
bile salt. After using the API $50 \mathrm{CHL}$ kit and species specific PCR, these strains were identified as L. fermentum. Thus, these two strains L. fermentum FTL2311 and L. fermentum FTL10BR were used for further studies.

Bile tolerance of $L$. fermentum FTL2311 and $L$. fermentum FTL10BR

Bile tolerance is one of the most crucial properties required for lactobacilli to survive in the small intestine, enabling them play a role in the physiological function of this organ. Bile salt can destabilise membrane integrity of bacterial cells. Good probiotic bacterial strain should survive in the presence of bile salts and be able to colonise the intestine surface. The concentration of bile salts used in this experiment was extremely higher compared to many other reports and it is used as a strong tool for selection of potential LAB. The wide variation of bile sensitivity was observed among various species of Lactobacillus $(6,13)$. In our study with the same species, results illustrated the variation of bile sensitivity between the two strains as shown in Table 1. The presence of oxgall caused more inhibitory effect to $L$. fermentum FTL2311 than for L. fermentum FTL10BR. Strains of $L$. fermentum FTL2311 showed more than $24 \mathrm{~h}$ delayed of growth in the presence of 5\% bile salt compared to only $3 \mathrm{~h}$ for L. fermentum FTL10BR. Shin et al. (33) have reported that strains of L. fermentum isolated from chicken cecum had growth delay of $2-4 \mathrm{~h}$ in the presence of $0.3 \%$ bile salt. In the present study at this low concentration of bile salt, the two selected strains demonstrated less than $1 \mathrm{~h}$ of growth delay. This indicated the high potential of bile tolerance of these two L. fermentum strains. The growth rate of L. fermentum FTL2311 was greatly affected with the addition of bile salt. This effect seemed to be concentration dependent. The relatively low concentration of about $0.3-1 \%$ inhibited not more than 5\% of L. fermentum FTL2311 growth whereas the higher concentrations of $2-5 \%$ of effectively decreased the growth of this strain more than $67-85 \%$. L. fermentum FTL10BR exhibited more bile salt tolerance. It was observed that with increasing of bile salt up to $5 \%$, only $35 \%$ growth inhibition of this strain occurred. Park et al. (25) examined the effect of bile concentration in the range of $0-5 \%$ on the $L$. acidophilus survival and they reported that L. acidophilus strains isolated from animal and human sources were suppressed over time and showed rapid decrease at 5\% bile salt. Consequently, L. fermentum FTL10BR isolated in our experiments could be classified as a strain with the highest potential of bile salt tolerance.

Table 1. The resistance of L. fermentum to bile salt (Oxgall, Difco, Detroit, MI, USA)

\begin{tabular}{ccccc}
\hline \multirow{2}{*}{$\begin{array}{c}\text { Bile } \\
\text { concentration } \\
(\%)\end{array}$} & $\begin{array}{c}\text { Delay } \\
\text { of }\end{array}$ & $\begin{array}{c}\text { FTL2311 } \\
\text { growth }^{\text {a }}\end{array}$ & $\begin{array}{c}\text { Delay } \\
\text { of }\end{array}$ & $\begin{array}{c}\text { FT } \\
\text { growth }^{\text {a }}\end{array}$ \\
\hline 0.3 & $<1 \mathrm{~h}$ & $97.9 \pm 2.7$ & $1 \mathrm{~h}$ & $81.1 \pm 2.7$ \\
0.5 & $1 \mathrm{~h}$ & $100.9 \pm 5.9$ & $3 \mathrm{~h}$ & $81.8 \pm 5.9$ \\
1 & $5 \mathrm{~h}$ & $95.9 \pm 0.1$ & $3 \mathrm{~h}$ & $85.9 \pm 0.1$ \\
2 & $8 \mathrm{~h}$ & $32.4 \pm 0.2$ & $3 \mathrm{~h}$ & $73.3 \pm 0.2$ \\
3 & $>24 \mathrm{~h}$ & $20.5 \pm 0.9$ & $3 \mathrm{~h}$ & $70.5 \pm 0.9$ \\
4 & $>24 \mathrm{~h}$ & $15.9 \pm 1.4$ & $3 \mathrm{~h}$ & $67.5 \pm 1.4$ \\
5 & $>24 \mathrm{~h}$ & $15.9 \pm 0$ & $3 \mathrm{~h}$ & $65.5 \pm 0.3$ \\
\hline & & & & \\
\hline
\end{tabular}

\section{The antibacterial activity of $L$. fermentum}

The rapid emergence of drug resistant strains and chronic toxicity $(4,21)$ of chemical antimicrobial agents following the widespread use of antibiotics encourage scientists to seek for the safety tools in treatment of bacterial infection. The use LAB with potential antimicrobial activity is the promising alternative treatment for such problems. The good probiotics should present their antimicrobial actions particularly to the pathogens in the GI system. In this study, L. monocytogenes 
DMST 17303, S. aureus, S. Typhi DMST 5784, and S. sonnei DMST 561 (ATCC 11060) were used as the test pathogenic bacteria because they are occasionally found as food borne pathogens. The selected two strains of L. fermentum showed antibacterial activities against the test bacteria however at different levels (Table 2.). The antagonistic activity exhibited by L. fermentum strains was further evaluated by the agarwell diffusion method. L. fermentum FTL10BR gave rather stronger inhibition against L. monocytogenes DMST 17303 whereas L. fermentum FTL2311 showed slightly better inhibitory effect against $S$. aureus subsp. aureus DMST 6512 (ATCC 6538Ptm). Both L. fermentum strains showed higher antagonistic activity against L. monocytogenes DMST 17303 and S. aureus subsp. aureus DMST 6512 (ATCC 6538Ptm) than $S$. Typhi DMST 5784 and S. sonnei DMST 561 (ATCC 11060). When the neutralized supernatants of L. fermentum strains were applied directly to the agar diffusion test, the signs of inhibition on most pathogenic bacteria could be observed indicating that the antibacterial activity was due to not only the acid components, but also to other substances produced by these two strains. Lin et al. (17) reported that $L$. fermentum isolated from swine and poultry showed antagonistic effect against gram negative bacteria such as Escherichia coli, Salmonella spp., Shigella sonnei, and gram positive bacteria, $S$. aureus. The results in our study indicated that L. fermentum strains isolated from miang were also pronounced the antibacterial activities against both gram positive and gram negative bacteria.

Table 2. Diameter of inhibition zone (mm) of L. fermentum strains FTL2311 and FTL10BR against pathogenic bacteria

\begin{tabular}{|c|c|c|c|c|}
\hline \multirow{2}{*}{ Pathogenic strains } & \multicolumn{2}{|c|}{ Agar spot assay $^{a}$} & \multicolumn{2}{|c|}{ Well assay $^{b}$} \\
\hline & FTL2311 & FTL10BR & FTL2311 & FTL10BR \\
\hline L. monocytogenes DMST 17303 & $7.4 \pm 1.5$ & $8.8 \pm 2.5$ & $8.2 \pm 1.1$ & $10.3 \pm 1.0$ \\
\hline S. aureus subsp. aureus DMST 6512 & $5.7 \pm 0.5$ & $4.7 \pm 1.3$ & $10.1 \pm 0.7$ & $10.0 \pm 0.8$ \\
\hline (ATCC 6538Ptm) & & & & \\
\hline S. Typhi DMST 5784 & $5.6 \pm 1.6$ & $5.2 \pm 0.9$ & $8.0 \pm 0.5$ & $7.0 \pm 0.6$ \\
\hline S. sonnei DMST 561 (ATCC 11060) & $3.6 \pm 0.6$ & $2.3 \pm 0.1$ & $7.0 \pm 0.5$ & $7.5 \pm 1.0$ \\
\hline
\end{tabular}

Effect of Bile Salt on Antibacterial Activity of $L$. fermentum against $S$. aureus subsp. aureus DMST 6512 (ATCC 6538Ptm)

The antagonistic activity of L. fermentum FTL10BR against $S$. aureus in the presence of oxgall was higher than that without bile. The antibacterial activity increased when the percentage of bile salt in media was increased. However, no distinct difference in antimicrobial power of L. fermentum srain FTL2311 against the pathogenic $S$. aureus subsp. aureus DMST 6512 (ATCC 6538Ptm) was observed when this strain was grown in the presence of different concentrations of bile. The data were shown in Table 3. Fernandes and Shanani (7) had worked on the effect of bile salts (sodium taurocholate and sodium glycholate) on antibacterial activity of $L$. acidophilus strains against Bacillus subtilis. They reported that the antibacterial activity of $L$. acidophilus decreased in the presence of bile salts. Hence, the effect of bile salt on antimicrobial activity was considered to 
be strain or species specific.

Table 3. Effect of bile concentrations on antibacterial activity of L. fermentum strains against $S$. aureus subsp. aureus DMST 6512 (ATCC 6538Ptm)

\begin{tabular}{ccc}
\hline $\begin{array}{c}\text { Bile concentration } \\
(\%)\end{array}$ & \multicolumn{2}{c}{ Antibacterial activity } \\
\cline { 2 - 3 } & L. fermentum & L. fermentum \\
FTL2311 & FTL10BR \\
\hline 0 & + & + \\
0.1 & + & + \\
0.3 & + & + \\
0.5 & + & + \\
1 & + & + \\
2 & + & ++ \\
3 & - & ++ \\
4 & - & ++ \\
5 & - & ++
\end{tabular}

$\begin{array}{ll}- & : \text { no inhibition zone } \\ + & : 6-10 \mathrm{~mm} \text { diameter of inhibition zone } \\ ++ & : 11-15 \mathrm{~mm} \text { diameter of inhibition zone }\end{array}$

Effects of $L$. fermentum on the ultrastructural morphology of the test pathogenic bacteria

The morphology of pathogenic L. monocytognes DMST 17303and S. aureus subsp. aureus DMST 6512 (ATCC $6538 \mathrm{Ptm})$ contacted with cell free of $L$. fermentum supernatant as observed by SEM demonstrated some critical changes as shown in Figure 1. Cells of $S$. aureus subsp. aureus DMST 6512 (ATCC 6538Ptm) and L.monocytogenes DMST 17303 in MRS broth without L. fermentum supernatant showed a regular, smooth surface as shown in Figure 1A and 1D, respectively. The pathogenic cells incubated with supernatant of each strain of L. fermentum revealed severe membrane damages consistent with disruption of the membrane integrity. The morphological abnormalities that occurred mainly due to the disruption of membrane structure were also reported by other authors when the strain of Escherichia coli, Mycobacterium chelonei, and Pseudomonas aeruginosa had been contacted with the wood oil of Japanese traditional tree (16). In this study, after exposure to the supernatant of L. fermentum FTL2311 and $L$. fermentum FTL10BR, S. aureus subsp. aureus DMST 6512 (ATCC 6538Ptm) revealed wrinkled abnormality on the cells as shown in Figure 1B and 1C, respectively. The crinkled cell morphology and cracked cells were observed in the cells of $L$. monocytogenes DMST 17303 after exposure to the supernatant of L. fermentum FTL2311 and FTL10BR as shown in Figure 1E and 1F, respectively. Such morphological changes in bacterial cells were considered to be due to the outer membrane lysis followed by loss of cellular electron dense material on the surface of treated pathogenic cells. The loss of electron dense material from the cells treated with supernatant indicated the loss of cell constituents and breakdown of the cell wall resulting in the release of essential cell materials. This study elucidated the antibacterial effects and some mechanism of action of L. fermentum extracellular secretion on the bacterial structure. Similar results were reported by Von Mollendorff et al. (39) that cell deformation and cell leakage of Lactobacillus sakei DSM 20017 were observed after tratment with bacteriocins of L. fermentum JW3BZ and JW6BZ.

\section{Antioxidant activity of $L$. fermentum}

The antioxidant activity of $L$. fermentum strains was determined by FRAP and ABTS methods with respect to reducing power and free radical scavenging activity and were expressed as EC and TEAC values, respectively. Results shown in Figure 2 indicated that the strains of L. fermentum FTL2311 and L. fermentum FTL10BR possessed antioxidant activity of both mechanisms but at different levels. The supernatant of L. fermentum FTL2311 and L. fermentum FTL10BR showed reducing power with EC values of


respectively. Compared to primrose oil, the natural material commonly use for antioxidant in cosmetic products, the supernatant of both strains had slightly less reducing power 
than this positive control. Interestingly, both strains showed the scavenging activity with TEAC values of $22.54 \pm 0.12$

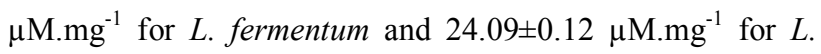
fermentum FTL10BR. These values were significantly higher than that of primrose oil. This finding of high free radical scavenging activity of both $L$. fermentum strains suggested a high efficacy of these strains as promising probiotics with potential antioxidant activity for health promotion of the host.


Figure 1. Scanning electron microscope images of $S$. aureus subsp. aureus DMST 6512 (ATCC 6538Ptm) (left) and $L$. monocytogenes DMST 17303 (right) cells, in control (MRS broth) (A and D), in the presence of supernatant of L. fermentum FTL 2311 (B and E), and in the presence of L. fermentum FTL 10BR (C and F).

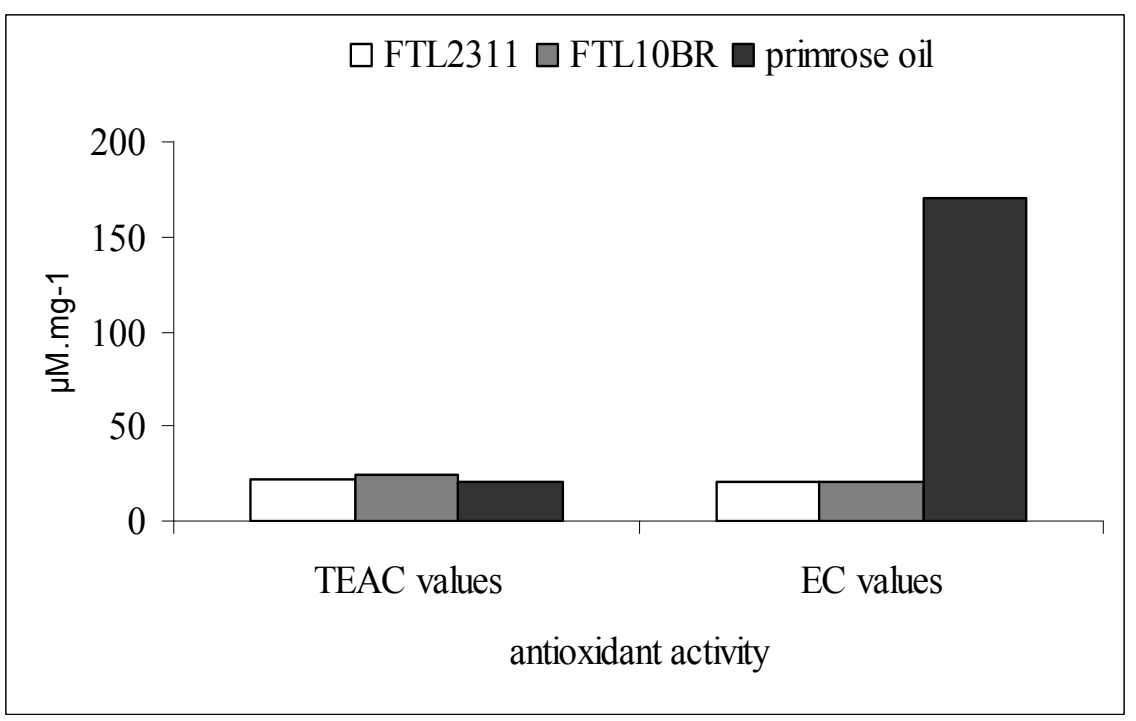

Figure 2. Free radical scavenging activity and reducing power of $L$. fermentum FTL2311, L. fermentum FTL10BR, and primrose oil. 
Based from results obtained in this study, it can be concluded that the two L. fermentum (L. fermentum FTL2311 and L. fermentum FTL10BR) isolated from miang possess a number of interesting important properties that constitute the requirement for their use as high potential probiotics with health-promoting properties but warrant further in vivo investigation.

\section{ACKNOWLEDGEMENTS}

This research was supported by the Thailand Research Fund (TRF). We wish to thank Mrs. Bussabong Kantalue for helping in the electron microscope analysis.

\section{REFERENCES}

1. Antolovich, M.; Prenzler, P.D.; Patsalides, E.; McDonald, S.; Robards, K. (2002). Methods for testing antioxidant activity. Analyst, 127, 183-198.

2. Aslima, B.; Yuksekdaga, E.; Sarikayab, Z.N.; Beyatli, Y. (2005). Determination of the bacteriocin-like substances produced by some lactic acid bacteria isolated from Turkish dairy products. Lebensm Wiss Technol., 38, 691-694.

3. Begley, M.; Hill, C.; Gahan, C.G.M. (2006). Bile Salt Hydrolase Activity in Probiotics. Appl. Environ. Microbiol., 72, 1729-1738.

4. Centikaya, Y.; Falk, P.; Mayhall, C.G. (2000). Vancomycin-resistant enterococci. Clin. Microbiol. Rev., 13, 686-707.

5. Deraz, S.F.; Hedström, M.; Karlsson, E.N.; Linse, S.; Khalil, A.A.; Mattiasson, B. (2007). Production and physicochemical characterization of acidocin D20079, a bacteriocin produced by Lactobacillus acidophilus DSM 20079. World J. Microbiol. Biotechnol., 23, 911-921.

6. Du Toit, M.; Franz, C.M.A.P.; Dicks, L.M.T.; Schillinger, U.; Haberer, P.; Warlies, B.; Ahrens, F.; Holzapfel, W. H. (1998). Characterisation and selection of probiotic lactobacilli for a preliminary minipig feeding trial and their effect on serum cholesterol levels, faeces $\mathrm{pH}$ and faeces moisture content. Int. J. Food Microbiol., 40, 93-104.

7. Fernandes, C.F.; Shanani, K.M.. (1988). Effect of nutrient media and bile salts on growth and antimicrobial activity of Lactobacillus acidophilus. J. Dairy Sci., 71, 3222-3229.

8. Forestier, C.; De Champs, C.; Vatoux, C.; Joly, B. (2001). Probiotic activities of Lactobacillus casei rhamnosus: in vitro adherence to intestinal cells and antimicrobial properties. Res. Microbiol., 152, 167-173.

9. Gardiner, G.E.; Heinemann, C.; Baroja, M.L.; Bruce, A.W.; Beverman, D.; Madrenas, J.; Reid, G. (2002). Oral administration of the probiotic combination Lactobacillus rhamnosus GR-1 and $L$. fermentum RC-14 for human intestinal applications. Int. Dairy J., 12, 191-196.

10. Gunn, J.S. (2000). Mechanisms of bacterial resistance and response to bile. Microb. Infect., 2, 907-913.

11. Henriksson, A.; Szewzyk, R.; Conway, P.L. (1991). Characteristics of the adhesive determinants of Lactobacillus fermentum 104. Appl. Environ. Microbiol., 57, 499-502.

12. Hyronimus, B.; Le Marrec, C.; Sassi, A.H.; Deschamps, A. (2000). Acid and bile tolerance of spore-forming lactic acid bacteria. Int. J. Food Microbiol., 61, 193-197.

13. Ibrahim, S.A.;. Bezkorovainy, A.. (1993). Survival of bifidobacteria in the presence of bile salt. J. Sci. Food Agri., 62, 351-354.

14. Kawakami, M.; Chairote, G.; Kobayashi, A. (1987). Flavor constituent of pickled tea, Miang, in Thailand. Agric. Biol. Chem., 51, 1683-1687.

15. Kiss, H.; Kögler, B.; Petricevic, L.; Sauerzapf, I.; Klayraung, S.; Domig, K.; Viernstein, H.; Kneifel, W. (2007). Vaginal Lactobacillus microbiota of healthy women in the late first trimester of pregnancy. BJOG: Int. J. Obst. Gyn., 114, 1402-1407.

16. Koyama, S.; Yamaguchi, Y.; Tanaka, S.; Motoyashiya, J. (1997). A new substance (yoshixol) with an interesting antibiotic mechanism from wood oil of Japanese traditional tree (kiso-hinoki), Chamaecyparis obtuse. Gen. Pharm., 2, 797-804.

17. Lin, W.H.; Yu, B.; Jang, S.H.; Tsen, H.Y. (2007). Different probiotic properties for Lactobacillus fermentum strains isolated from swine and poultry. Anaerobe, 13, 107-113.

18. Makras, L.; Triantafyllou, V.; Fayol-Messaoudi, D.; Adriany, T.; Zoumpopoulou, G.; Tsakalidou, E.; Servin, A.; De Vuyst, L. (2006). Kinetic analysis of the antibacterial activity of probiotic lactobacilli towards Salmonella enterica serovar Typhimurium reveals a role for lactic acid and other inhibitory compounds. Res. Microbiol., 157, 241-247.

19. Mante, E.S.; Sakyi-Dawson, E.; Amoa-Awua, W.K. (2003). Antimicrobial interactions of microbial species involved in the fermentation of cassava dough into agbelima with particular reference to the inhibitory effect of lactic acid bacteria on enteric pathogens. Int. J. Food Microbiol., 89, 41-50.

20. Margolles, A.; García, L.; Sánchez, B.; Gueimonde, M.; De Los Reyes-Gavilán, C. (2003). Characterisation of a Bifidobacterium strain with acquired resistance to cholate-A preliminary study. Int. J. Food Microbiol., 82, 191-198. 
21. Mody, L.; Kauffman, C.A.; McNeil, S.A.; Galecki, A. T.; Bradley, S.F. (2003) Mupirocin-based decolonization of Staphylococcusaureus carriers in residents of 2 long-term care facilities: a randomized, double-blind, placebo-controlled trial. Clin. Infect. Dis., 37, 1467-1474.

22. Mojgani, N.; Torshizi, M.A.K.; Rahimi, S. (2007). Screening of locally isolated lactic acid bacteria for use as probiotic in poultry in Iran. J. Poult. Sci., 44, 357-365.

23. Ouwehand, A.C.; Salminen, S.; Isolauri, E. (2002). Probiotics: an overview of beneficial effects. Antonie Van Leeuwenhoek, 82, 279289.

24. Papamanoli, E.; Tzanetakis, N.; Litopoulou-Tzanetaki, E.; Kotzekidou, P. (2003). Characterization of lactic acid bacteria isolated from a Greek dry-fermented sausage in respect of their technological and probiotic properties. Meat Sci., 65, 859-867.

25. Park, S.C.; Hwang, M.H.; Kim, Y.H.; Kim, J.C.; Song, J.C.; Lee, K.W.; Jeong, K.S.; Rhee, M.H.; Kim, K.S.; Kim, T.W. (2006). Comparison of $\mathrm{pH}$ and bile resistance of Lactobacillus acidophilus strains isolated from rat, pig, chicken, and human sources World J. Microbiol. Biotech., 22, 35-37.

26. Pennacchia, C.; Ercolini, D.; Blaiotta, G.; Pepe, O.; Mauriello, G.; Villani, F. (2004). Selection of Lactobacillus strains from fermented sausages for their potential use as probiotics. Meat Sci., 67, 309-317

27. Pereira, D.I.; Gibson, G.R. (2002). Effects of consumption of probiotics and prebiotics on serum lipid levels in humans. Crit. Rev. Biochem. Mol. Biol., 37, 259-281.

28. Reid, G.; Bruce, A. W.; Fraser, N.; Heinemann, C.; Owen, J.; Henning, B. (2001). Oral probiotics can resolve urogenital infections. FEMS Immunol. Med. Microbiol., 30, 49-52.

29. Reque, E.F.; Pandey, A.; Franco, S.G.; Soccol, C.R. (2000). Isolation, identification and physiological study of Lactobacillus fermentum LPB for use as probiotic in chickens. Braz. J. Microbiol., 31, 303-307.

30. Rojas, M.; Ascencio, F.; Conway, P.L. (2002). Purification and character- ization of a surface protein from Lactobacillus fermentum 104R that binds to porcine small intestinal mucus and gastric mucin.
Appl. Environ. Microbiol., 68, 2330-2336.

31. Saarela, M.; Mogensen, G.; Fondén, R.; Mättö, J.; MattilaSandholm, T. (2000). Probiotic bacteria: Safety, functional and technological properties. J. Biotechnol., 84, 197-215.

32. Schillinger, U.; Lücke, F.K. (1989). Antimicrobial activity of Lactobacillus sake isolated from meat. Appl. Environ. Microbiol., 55, 1901-1906.

33. Shin, J.W.; Jong, K.K; Keum-Il, J.; Kwang, Y.K. (2002). Intestinal colonization characteristics of Lactobacillus spp. isolated from chicken cecum and competitive inhibition against Salmonella typhimurium. J. Microbiol. Biotechnol., 12, 576-582.

34. Song, Y.; Kato, N.; Liu, C.; Matsumiya, Y.; Kato, H.; Watanabe, K. (2000). Rapid identification of 11 human intestinal Lactobacillus species by multiplex PCR assays using group- and species-specific primers derived from the 16S-23S rRNA intergenic spacer region and its flanking 23S rRNA. FEMS Microbiol. Lett., 187, 167-173.

35. Tachakittirungrod, S.; Okonogi, S.; Chowwanapoonpohn, S. (2007). Study on antioxidant activity of certain plants in Thailand: Mechanism of antioxidant action of guava leaf extract. Food Chem., $103,381-388$.

36. Tanasupawat, S.; Pakdeeto, A.; Thawai, C.; Yukphan, P.; Okada, S. (2007). Identification of lactic acid bacteria from fermented tea leaves (miang) in Thailand and proposals of Lactobacillus thailandensis sp. nov., Lactobacillus camelliae sp. nov., and Pediococcus siamensis sp. nov. J. Gen. Appl. Microbiol., 53, 7-15.

37. Tsai, C.C.; Hsih, H.Y.; Chiu, H.H.; Lai, Y.Y.; Liu, J.H.; Yu, B.Y.; Yang Tsen, H.T. (2005). Antagonistic activity against Salmonella infection in vitro and in vivo for two Lactobacillus strains from swine and poultry. Int. J. Food Microbiol., 102, 185- 194.

38. Von Mollendorff, J.W.; Todorov, S.D.; Dicks, L.M.T. (2006). Comparison of bacteriocins produced by lactic-acid bacteria isolated from Boza, a cereal-based fermented beverage from Balkan. Curr. Microbiol., 53, 209-216..

39. Von Mollendorf, J.W.; Todorov, S.D.; Dicks, L.M.T. (2007). Factor Affecting the adsorption of bacteriocins to Lactobacillus sakei and Enterococcus sp. Appl. Biochem. Biotechnol., 142, 209-220. 